\title{
Endovascular approaches to the ascending aorta are right around the corner
}

\author{
George J. Arnaoutakis, MD, and Wilson Y. Szeto, MD
}

\footnotetext{
From the Division of Cardiovascular Surgery, University of Pennsylvania, Philadelphia, Pa.

Disclosures: W.Y.S. serves as Consultant/Advisory Board, Micro Interventional Devices, Inc; and receives research grants from Edwards Lifesciences Corporation, Medtronic, Inc, LivaNova, and Bolton Medical. The other author has nothing to disclose with regard to commercial support.

Received for publication March 5, 2016; accepted for publication March 8, 2016; available ahead of print April 5, 2016.

Address for reprints: Wilson Y. Szeto, MD, Division of Cardiovascular Surgery, Penn Presbyterian Medical Center, University of Pennsylvania, 51 N 39th St, Heart and Vascular Pavillion 2A, Philadelphia, PA 19104 (E-mail: wilson.szeto@uphs.upenn.edu).

J Thorac Cardiovasc Surg 2016;152:285-6

$0022-5223 / \$ 36.00$

Copyright (C) 2016 by The American Association for Thoracic Surgery

http://dx.doi.org/10.1016/j.jtcvs.2016.03.024
}

Endovascular technology has revolutionized the surgical management for patients with descending thoracic aortic pathology. Over the last decade, there has been growing interest in applying these technologies to treat various pathologies of the aortic arch and ascending aorta, primarily acute type A aortic dissection and ascending aortic pseudoaneurysm (AAP) (Figure 1). Several technical challenges remain, however. These include the complex anatomy of the aortic root; the close spatial relationships among the aortic root, ascending aorta, and aortic arch; and device dimensions currently designed for the descending thoracic aorta. Despite increasing experience with endovascular approaches to ascending aortic pathology, most published series to date are confined to patients deemed high risk for open surgical repair. $^{1-3}$

In this article, $\mathrm{Li}$ and colleagues ${ }^{4}$ report their use of intraoperative transesophageal echocardiography and a 3D printing model to customize a nitinol mesh occlusion device for treatment of a large AAP. Interestingly, the etiology of this AAP was never elucidated. This creative technique is novel in its application of a 3D model derived from computed tomography images. The AAP was approached directly through a sternotomy incision, although this same intervention could conceivably could be done through a transapical left anterior thoracotomy approach, which has been described previously. ${ }^{5}$ The AAP was relatively large, with a $\sim 2-\mathrm{cm}$ neck. The authors fashioned the occlusion device off the 3D model to ensure proper sizing and achieve an effective seal and durable fixation.

Presumably, the need to customize design of the occlusion device limits application to the nonemergency setting. Immediate and short-term follow-up imaging demonstrated effective obliteration of the pseudoaneurysm. The authors elected to not use anticoagulation owing to the hemodynamic forces in the ascending aorta, although data to guide this decision are lacking.

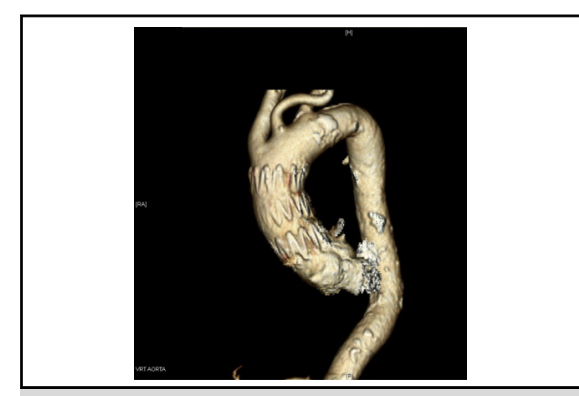

A Cook Zenith TX2 graft deployed via the transapical approach for acute type A dissection.

\section{Central Message}

In the future, endovascular techniques will likely be widely applicable for treatment of selected ascending aortic pathology.

See Article page 282.

This case description highlights several important points regarding innovation and the application of new technology and imaging modalities to treat various pathologies of the ascending aorta. First, innovation in surgery begins with

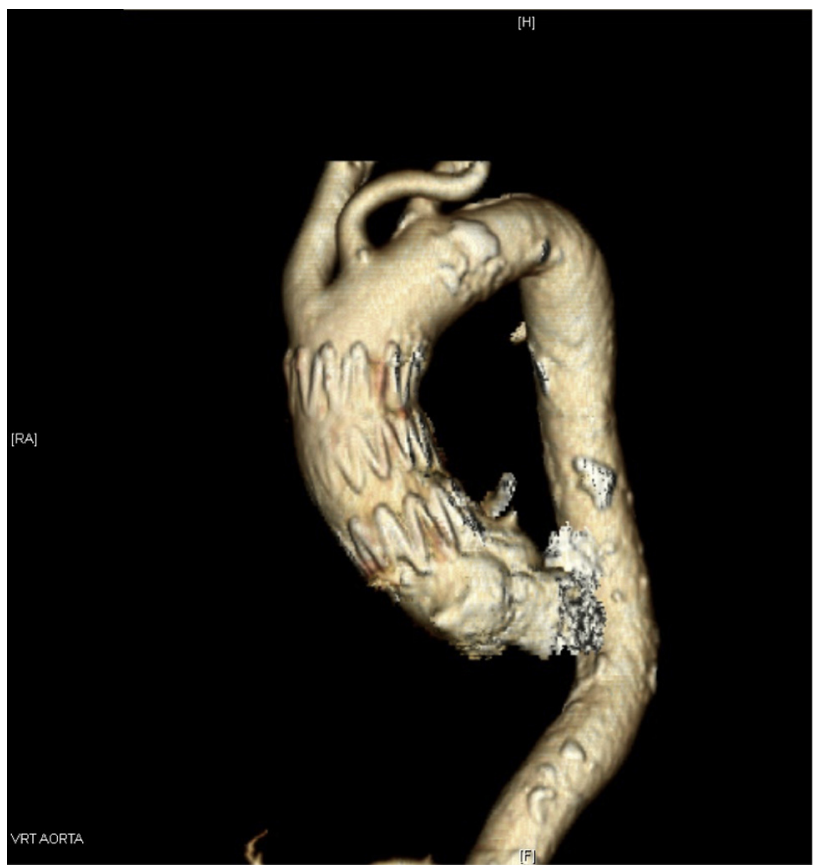

FIGURE 1. Cook Zenith TX2 graft (Cook Medical, Bloomington, Ind) deployed via the transapical approach for acute type A dissection. 
building a conceptual framework to address a clinical problem. Several centers have begun to embrace the concept of an endovascular remedy for ascending aorta pathology. The referenced case series demonstrates proof of feasibility for this conceptual approach. Only additional larger-scale trials will be able to identify the long-term clinical effectiveness of this approach.

Second, cardiothoracic surgical innovation requires both entirely new design technology as well as refinements in existing technology. This is especially true in treatment of the ascending aorta, where we currently must improvise, using devices designed and studied for deployment in other anatomic locations. These devices are commonly taken off the shelf and used in an off-label setting. It is incumbent on the cardiothoracic surgical community to partner with the endovascular technology industry to develop diseasespecific devices for the ascending aorta.

Finally, as in the case with transcatheter aortic valve replacement technology, cardiothoracic surgeons must be early adopters of these new technologies for the ascending aorta. We should participate and embrace clinical trials designed to address ascending aorta pathology with endovascular techniques with the goal of improving patient care and outcome. This is a vital responsibility for us at an exciting time when traditional surgical approaches are being encroached on by novel, minimally invasive solutions to treat nearly the entire spectrum of cardiothoracic pathology.

$\mathrm{Li}$ and colleagues ${ }^{4}$ should be commended for their creative use of 3D modeling, transesophageal echocardiography imaging, and customized device design to address ascending aorta pseudoaneurysm, which can pose a significant risk for traditional open repair.

\section{References}

1. Piffaretti G, Galli M, Lomazzi C, Franchin M, Castelli P, Mariscalo G, Trimarchi S. Endograft repair for pseudoaneurysms and penetrating ulcers of the ascending aorta. J Thorac Cardiovasc Surg. 2016;151:1606-14.

2. Roselli EE, Idrees J, Greenberg RK, Johnston DR, Lytle BW. Endovascular stent grafting for ascending aorta repair in high-risk patients. J Thorac Cardiovasc Surg. 2015;149:144-51.

3. Vallabhajosyula P, Gottret JP, Bavaria JE, Desai ND, Szeto WY. Endovascular repair of the ascending aorta in patients at high risk for open repair. $J$ Thorac Cardiovasc Surg. 2015;149(2 Suppl):S144-50.

4. Li F, Shan Y, Zhang Y, Niu G. Occlusion of an ascending aortic pseudoaneurysm with intraoperative echocardiography and a printed model. J Thorac Cardiovasc Surg. 2016;152:282-4.

5. Szeto WY, Moser WG, Desai ND, Milewski RK, Cheung AT, Pochettino A, et al. Transapical deployment of endovascular thoracic aortic stent graft for an ascending aortic pseudoaneurysm. Ann Thorac Surg. 2010;89:616-8. 